\title{
Library research in the future:
}

\section{A prognostication}

\author{
By Philip H. Young \\ Director, Krannert Memorial Library \\ University of Indianapolis
}

\section{One librarian's speculative bibliographic scenario.}

$\mathbf{L}$ dict the future course of their profession. For academic librarians especially, one important aspect of prognostication concerns how a researcher of the future will access information and use it in the creation of a new document. Let's do some "blue-sky" dreaming about what that future might be like.

The research environment will be comfortable, quiet, and conducive to efficient brain functioning. The furniture will be ergonomically pleasing and the surroundings free of disruptions. In this comfortable setting will be located the tools of research: information sources, means to record and excerpt important passages, and a tabula rasa upon which to create new syntheses, ideas, and promulgations. Appropriate processing tools will be readily available for the manipulation of data and words and the eventual perfection of a new document.

Most important for the researcher is access to the materials that he/she needs to consult and digest while studying a topic of interest. To achieve this goal there will be a computer-driven research station with the capability of linking him or her either to the information sources directly or to remote sources which will provide them quickly. The researcher will be able to communicate with this terminal (for lack of a better word) as easily and naturally as possible, i.e., by voice. The terminal will itself be an "intelligent" machine with the ability to learn the researcher's interests as the work progresses and suggest possible alternate research routes along the way. The terminal's access to a wide array of information resources and strategies will be transparent to the researcher so as not to impede his or her thought processes. The terminal will be able to shift between information searching and its other functions without pause and, if needed, perform various functions at once so that, for example, the researcher could be reviewing an information source at the same time as composing notes inspired by it.

The computer terminal will be the linking agent between the researcher and various information resources and between the researcher and a finished product, be it notes for future reference or a document for publication. The initial interchange between researcher and terminal will resemble a reference interview with the researcher stating the topic of interest and the terminal discovering what scope and type of information is needed. The terminal will then make connections to appropriate resources and search for information on the researcher's subject of interest. During this process, the terminal may have to check with the researcher for clarification about the research topic in order to narrow or expand the search and to report initial findings in order to check whether search strategies in process are on the right track. Materials in all formats will be recovered, if the researcher wants them, and citations will appear clearly and con- 
cisely (without abbreviations, code terms or numbers, tight spacing, etc.)

When the initial information search is complete and useful items or citations to them are recovered, the researcher will be able to proceed directly to work. Remotely held materials will be automatically ordered and notices as to delivery time will be reported. Materials available online will be displayed immediately or printed out on a connected printer, if so preferred. While perusing online materials, the researcher will be able by voice communication to move sentences, paragraphs, or other selections into a holding area and reorganize them or add his or her own comments and observations as the research progresses. Footnotes as to sources will be generated automatically so that the researcher will know whence information items derived but will not get bogged down with the chore of remembering to ask for citations for each item. The researcher will be able to mark certain elements of his or her notes for special recall or sorting later.

Finally, the researcher will be able to review and organize the information recovered, along with his or her personal insights and developments and will be able to use these notes to build a final report document. The notes will be able to be sorted and resorted as needed with source footnotes always following and accessible. The notes will be able to be manipulated alongside the new document being created so that both are visible at the same time. Useful tools, such as thesauri, dictionaries, fact and date lists, etc., will be available for instant online consultation as needed. All formatting and other word-processing functions will be handled automatically or by voice command if defaults are not adequate.

It may be hard to visualize how the process outlined above might operate, so let's imagine a research session of the future. Our patron, Nancy Bookwright, enters an available library research carrel assigned to her at the front desk, closes the soundproof door to the room, and switches on the computer terminal's power supply switch. As she sits down in the comfortable chair facing the large screens built into the desk top, the center screen displays the library's logo, and a soft computergenerated voice says, "Good afternoon, are you ready to begin an information search?" After Nancy's affirmative reply, the voice requests her to read a standardized sentence aloud so that the terminal can adjust its voice-recognition circuits for her accent and individual pronunciation. Then, the voice says, "What topic would you like to search for today?"

"I am interested in the battle of Marathon," she replies, watching the almost instantaneous appearance of the words on the screen. A split second later, a short encyclopedia paragraph appears below the request.

"Are you referring to the battle between the ancient Greeks and the Persians fought in 490 B.C.?" queries the terminal's voice. After Nancy's "yes," the voice continues, "Do you need general information or specific research-level materials on this topic?"

"I need to review all the research done in the last fifty years," says Nancy, leaning back in her chair.

"I am beginning the search now," responds the terminal as its screen displays the words "Search in Process."

During this interchange, the terminal has already formulated a search strategy and accessed a massive database composed of all terms used in titles and abstracts of virtually all periodical literature for the past decade. While accessing this retrospective periodicals database and the national book catalog, the terminal presents citations and abstracts of three articles from the initial search. "Here are three recent articles that seem to be on your topic. While I am accessing earlier records, would you like to view the full text or have a printout?"

Nancy skims the titles and abstracts and notices that one of the articles is about the price battles of Marathon Oil Company with a competitor and that she has already read another one of the articles. "Please show the full text of citation two," she replies. A new screen is activated and the text of the requested article is presented on the right side of the desktop display. Meanwhile, a citation appears on the left side and the terminal's voice says, "I have only found one book dealing with your topic. The search term is not in the title, but the table of contents refers to it." Below the citation, the table of contents has now appeared on the screen. The voice continues. "This book is presently in the library. Would you like to have it delivered?"

"Yes, please," responds Nancy. While the terminal is signaling a library page working in the appropriate section of the stacks to find the book and deliver it to the window slot in Nancy's carrel, our researcher is reading the article on the right side of the screen. "Save the third paragraph," she says, and the terminal adds a section below the scrolling text where the paragraph and its source citation appear. Other sections are saved and personal comments added as our researcher works through the article. Within a few minutes, the book slot beside the carrel's door swings open and the requested book appears on the shelf there, already checked out to her by the terminal's communication with the circulation computer. Nancy reaches for the book and begins to read it, again making verbal notes as she proceeds.

The terminal's pleasant voice interrupts: "There are five retrospective articles on your topic in the time range you specified. Only two of them have full text available online. Of the other three, the library holds hard copy of two of them and I have ordered them for delivery to you. Would you like to request the third one on Interlibrary Telefacsimile?" After Nancy's affirmative response, the voice continues, "For the two available online, 
would you like to view the full text or have printouts?" Nancy requests printouts because she is still busy with the book source, and a high-speed, quiet printer whirs and deposits several sheets in the bin near Nancy's chair.

Well, let's leave our patron of the future at work and return to the present to analyze this vision of future information access and scholarly research. The work place which we have envisioned is certainly nothing which could not be available now. I have situated it in a library, but other than quick delivery of materials not available online there is no reason that it could not be located anywhere, such as in the researcher's private office or even at home. The details of comfortable chair and quiet atmosphere were included to make the point that present libraries tend to feel sterile and institutional. Noise from people passing or talking can be bothersome to researchers, and the lack of privacy, uncomfortable furniture, poor lighting, etc., decrease their comfort.

Central to our vision of the future is the terminal through which our researcher accesses information sources, conducts her research, incorporates her own opinions, analyses, and observations, and creates a final product. I have endowed the imaginary terminal with intelligent voice communication capability, although the above exchanges could have occurred on-screen just as well. Computer experts are working on voice recognition systems for word processing right now and have prototypes already operational. Current research emphasis is being placed on artificial intelligence and expert systems for computers, and the vision of a terminal with rather sophisticated voice interaction and "learning" capability does not seem to be too far down the road.

Our hypothetical terminal's other functions are, again, logical combinations of or expansions on presently available technology or systems. After the terminal has determined what search terms and qualifiers are needed for Nancy's search, it proceeds to access appropriate periodicals databases, perhaps more comprehensive than our BRS or DIALOG but similar to them. The terminal then accesses a national book database not unlike OCLC or RLIN but with the capability to review tables of contents, a development already under discussion today. Finally, the terminal accesses the holdings of its own library to check whether the desired citations match locally held items. Again, online catalogs are not new, but the automatic linkage with search services would be innovative. The terminal's ability to perform all these tasks simultaneously represents vast memory expansion over present computers, as well as elaborate artificial intelligence structures to direct activities and output. However, the trend towards lower memory cost and the potential advent of new storage technologies make me think such hypotheses not too farfetched.

Most important to our vision of future research is the rapid document delivery imagined. The concept of having a terminal go beyond telling a researcher that the library owns a book to having it page someone to get it off the shelf and deliver it to a certain location seems only an extension of present online catalog capabilities. Similarly, the ability to request an item recovered as a citation through an extension of the initial search using rapid library to library telefacsimile service is a combination of present technical capabilities. Probably the most novel aspect of our imaginary researcher's document recovery is the ability to view (or download and print) full texts of journal articles. However, with the already noted advances being made in computer memory and storage technologies, perhaps the day will come when journals will either be scanned digitally for online availability or will simply have their texts distributed and maintained electronically.

Where would this picture of future research leave libraries? I believe the in-depth and wellpackaged collections of knowledge that we know as books will not disappear or be transformed into electronic storage anytime in the near future due to the immense amount of data they make available, especially retrospectively. This observation may also hold for periodicals, but I think, as indicated in the above scenario, that it is more likely that this medium may become electronic in the not too distant future. Thus, libraries will still be needed as repositories of information in hard copy with the requisite needs to organize it and make it available as efficiently as possible. Instead of people browsing the stacks, we may have them browsing electronically, but they will still need the document to be delivered as quickly as possible. Libraries will need to reorganize their thinking towards delivering books to patrons using research stations in the building or in remote locations.

Librarians will still need to select and collect books and non-book materials for their patrons' use and they will have to develop efficient means of moving documents from library to library for swift delivery of items not held. Since the agent of access will be computer-driven terminals, programs of instruction on their use will be required, as well as more general instruction programs on the nature of information itself and what formats and presentations of it are likely to be available. In the scenario presented above, the researcher had already defined a very specific topic of interest but, in fact, many information seekers will require the assistance of librarians to help them focus their needs sufficiently to utilize the intelligent terminal's search capabilities. Most importantly, librarians will have to oversee and manage the complex communications systems and linkages to information providers which will be the life-blood of the intelligent terminals' ability to match researcher with documents.

In the future, as now, a researcher will want to locate materials of interest, get the documents in 
hand, and study them as efficiently as possible in the most comfortable surroundings, with the fewest interruptions, and the least "red tape." The librarian of the future will be using new equipment and amazing computer linkages of data management systems but will still have the same mission as in the past: to collect, organize, and make available the information needed by researchers; to provide appropriate equipment to access, service, and update that information; and to train patrons to use information sources efficiently and effectively.

\section{Optical disk-based periodical}

\section{indexes for undergraduates}

\author{
By Lori E. Buchanan \\ User Education Librarian \\ Austin Peay State University
}

\author{
Anne May Berwind \\ Head, Information Services Department \\ Austin Peay State University
}

and Don Carlin

Information Services Librarian

Austin Peay State University

\section{Local library coverage and success rate as criteria for selecting an index.}

$\mathbf{F}$ aced with a growing number of choices and limited budgets, academic libraries must carefully consider the goals they wish to achieve with optical disk-based periodical indexes. The initial investment is especially important for two reasons. First, the product chosen introduces the campus community to the technology. Second, it sets the stage for future optical disk acquisitions. The goals for each library are different. In one library, optical disks are seen as an alternative to online database searching. In another library, they are viewed as an exciting, new way to introduce lower-division undergraduates to the research process. Once a library sets its goals, the optical disk products likely to meet these goals are selected for evaluation. Several re- cent articles which outline the evaluation or selection of optical disk products are found in the library literature. ${ }^{1}$ These articles provide good background information for libraries considering the purchase of an optical disk-based periodical index. However, they do not document an evaluation pro-

\footnotetext{
${ }^{1}$ Notable examples are: David C. Miller, “Evaluating CD-ROMS: To Buy or What to Buy?" Database, June 1987, pp. 36-42; Gail T. Graves, Laura G. Harper, and Beth F. King, "Planning for CDROM in the Reference Department," College and Research Libraries News, July/August 1987, pp. 393-400; Linda Stewart, "Evaluation Criteria: Picking CD-ROMS for Public Use," American $L i$ braries, October 1987, pp. 738-40.
} 